Sección Tres: Experiencias, reseñas, debates e informes

Mujer y Educación. Un largo camino hacia la igualdad

\title{
La Mujer Anglosajona y su legado feminista: Guía Didáctica de Mujeres Anglosajonas en lengua inglesa para el alumnado de ESO y Bachillerato ${ }^{1}$
}

The Anglo-Saxon women and their feminist legacy: An English Didactic Guide on AngloSaxon-women aimed at Secondary Education students

Patricia Marín del Ojo

Universidad de Cádiz

patricia.marindelojo@alum.uca.es

\section{Reseña de un Trabajo de Fin de Máster}

En este monográfico presentamos el resumen del Trabajo de Fin de Máster (TFM) titulado "La Mujer Anglosajona y su legado feminista: Guía Didáctica de Mujeres Anglosajonas en lengua inglesa para el alumnado de ESO y Bachillerato.", conducente a la obtención del Máster Universitario en Profesorado de Educación Secundaria Obligatoria, y Bachillerato, FP y Enseñanza de Idiomas, tutorizado por la doctora Lucía-Pilar Cancelas-Ouviña y defendido en la Universidad de Cádiz en julio de 2020. Este trabajo constituye una propuesta de innovación docente enmarcada en los Estudios de Género. Nuestro producto final es una Guía Didáctica que pretende ayudar al profesorado de ESO y Bachillerato a incluir la perspectiva de género en el aula de idiomas a la vez que se ocupan de la enseñanza de la lengua inglesa y sus aspectos socioculturales. También puede utilizarse en la educación bilingüe en disciplinas no-lingüísticas que aborden esta temática.

\section{Introducción y objetivos}

Esta Guía Didáctica se vertebra en torno a dieciséis mujeres anglosajonas (científicas, escritoras, pintoras...) cuyas hazañas lograron desafiar al sistema androcéntrico, convirtiéndose en pioneras en la defensa de los derechos de la mujer. Por ello, el propósito de este TFM es acercar a los jóvenes y adolescentes al estudio de la realidad femenina, así como ofrecerles modelos de mujeres replicables que les sirvan de acicate e inspiración.

Puesto que el deseo de un cambio social feminista ya se puede apreciar en las mujeres

${ }^{1}$ Recibido: 19/05/2017 Evaluado: 23/06/2017 Aceptado: 25/06/2017

No 9, 2021. Página| 339 
anglosajonas desde el siglo XVIII, en este TFM, se analiza el desarrollo de la pugna por los derechos de género en el transcurso de los últimos siglos. El tratamiento de los aspectos socioculturales constituye un pilar básico en la enseñanza de las lenguas extranjeras, por ello, en la elaboración de esta Guía Didáctica hemos recurrido al patrimonio artístico y cultural como fuente de enriquecimiento y desarrollo personal.

El objetivo de este TFM es, principalmente, elaborar y diseñar una amplia gama de recursos didácticos de modo que ayude al profesorado de ESO y Bachillerato a integrar la perspectiva de género en el aula de Inglés, así como mejorar la competencia lingüística en L2 de los estudiantes.

En cuanto a los objetivos específicos de aprendizaje para el alumnado de Educación Secundaria, en esta Guía cabe destacar los siguientes:

- Aprender léxico básico sobre género en L1 y L2 y utilizarlos en contextos reales de comunicación.

- Expresarse, debatir e interactuar de manera oral y escrita en L2 sobre el androcentrismo, la discriminación de género, las sexualidades y los derechos humanos.

- Leer y comprender textos diversos relacionados con la lucha feminista en lengua inglesa, utilizando la lectura en distintos soportes.

. Estimular la creatividad de los estudiantes mediante actividades lúdicas e interactivas que posicionen al discente como protagonista de su proceso de enseñanza-aprendizaje.

\section{Marco teórico}

Según Ryan (2007), hoy en día, la mujer sigue estando sometida, de manera universal, al poder de la sociedad androcéntrica. De hecho, algunas críticas llegaron a constatar que la mujer siempre ha estado definida como "La Otra", manera en la que se define - a este rol en la obra magistral El Segundo Sexo de Simone de Beauvoir (1949). Si bien el rol de la mujer ha cambiado considerablemente con el paso de los años, variando, además, de una cultura a otra, aún no se ha erradicado la brecha de género.

Por consiguiente, en este TFM, consideramos la educación como el principal motor de cambio, crucial para sentar las bases que ayuden a paliar esta situación de desigualdad. Sin embargo, puesto que la educación androcéntrica persiste, el sustento teórico que sostiene esta Guía Didáctica se puede localizar en la pedagogía feminista. Es una teoría que nace desde la interseccionalidad, relacionada con la búsqueda de la justicia de género. La pedagogía feminista concibe el aula como un espacio de liberación donde tanto el alumnado como el profesorado forman parte activa del proceso de enseñanza-aprendizaje (Shrewsbury, 1997).

Así pues, el papel del profesorado y su práctica docente son de vital importancia a la hora de impulsar y transmitir ciertos valores. Las escritoras Freixas y Fuentes (1994) proponen que el equipo docente reflexione sobre estas cuestiones: primero, que se replantee el rol del género dentro de su disciplina, segundo, que ponga en cuestión las estructuras básicas sobre las que se ha construido su disciplina y tercero, que revise sus actitudes e interacciones durante la enseñanza; y eso es precisamente lo que nos planteamos en esta investigación.

No 9, 2021. Página $\mid 340$ 


\section{Diseño y estructura de la Guía Didáctica}

El criterio de selección por el que nos hemos regido ha venido dado por la actitud transgresora e independiente de las mujeres anglosajonas, precursoras de los valores propugnados por la lucha feminista que constituyeron las bases del cambio. Ellas denunciaron toda forma de represión, identificaron los obstáculos existentes en la estructura socioeconómica y ofrecieron al feminismo un sentimiento de sororidad.

En lo referente a la estructura de la Guía Didáctica, esta se divide en cuatro unidades temáticas, clasificadas por actividades de diversa índole. La primera, "Scientists can also be women" plantea las nociones básicas sobre el sistema sexo-género. Se toman de referente a cuatro mujeres científicas de mediados del siglo XIX - Margaret Ann Bulkley (1795-1865), Maria Mitchell (1818-1889), Florence Nightingale (1820-1910), Marianne North (18301890) - con motivo de conocer los estereotipos de género propios de la época victoriana.

La segunda, titulada "Activists and Suffragettes", pone de manifiesto la lucha social y política llevada a cabo por las mujeres británicas que formaron parte del movimiento sufragista Emmeline Pankhurst (1858-1928), Constance Lloyd (1859-1898), Marion Wallace Dunlop (1865-1942), Emily Davison (1872-1913). A continuación, la unidad "Women during the World Wars" constituye una crítica a los roles tradicionales de género asignados al hombre y a la mujer durante la Primera y Segunda Guerra Mundial; nuestras mujeres referentes son Olive Mudie-Cooke (1890-1925), Vera Brittain (1893-1970), Freya Stark (1893-1993) y Edith Nesbit (1858-1924).

La cuarta y última, "The feminist legacy", explora la realidad femenina desde la poesía y la música envuelta en la segunda ola feminista con mujeres tan emblemáticas como: Virginia Woolf(1882-1941), Sylvia Plath (1932-1963), Gladys Bentley (1907-1960) y Faith Ringgold (1930). Como colofón, el profesorado encontrará un glosario de género, así como las biografías de cada una de las mujeres seleccionadas.

En su diseño se propone una metodología basada en técnicas y estrategias de aprendizaje cooperativo ya que se trata de un método inclusivo que favorece la atención a la diversidad y fomenta el pensamiento crítico. Asimismo, las TIC constituye el principal material de apoyo para la ejecución de las sesiones, potenciando la motivación y participación del alumnado. Además, los materiales y testimonios auténticos han sido esenciales para lograr un aprendizaje de los aspectos socioculturales del mundo anglosajón, así como los valores de igualdad y defensa de la dignidad femenina recogidos en los derechos humanos.

En definitiva, la ambición fundamental de este trabajo es luchar por el avance social, el cual solo puede lograrse a través de hechos y no palabras, tal y como la sufragista más ferviente, Emmeline Pankhurst, reclamaba allá en el año 1914: "Deeds, not words, was to be our permanent motto" (p.38).

\section{Referencias}

$\mathrm{N}^{\circ}$ 9, 2021. Página| 341 
De Beauvoir, S. (1952). The Second Sex. Nueva York: Knopf.

Freixas, A. \& Fuentes-Guerra, M. (1994). La reflexión sobre el Sistema sexo/género. Un reto en la actual formación del profesorado. Revista Educación, 304, 165-176.

Pankhurst, E. (1914). My Own Story. England: Virago.

Ryan, M. (2007). Literary Theory. A Practical Introduction. Oxford: Blackwell.

Shrewsbury, C. (1997). What is feminist pedagogy? Women's Studies Quartely, 15(1/2), 166173.

\section{Legislación:}

Decreto 111/2016, de 14 de junio, por el que se establece la ordenación y el currículo de la Educación Secundaria Obligatoria. Boletín Oficial de la Junta de Andalucía (BOJA, núm. 122), 28 de junio de 2016. 